\title{
A 12-month clinical evaluation of pit-and-fissure sealants placed with and without etch-and-rinse and self-etch adhesive systems in newly-erupted teeth
}

\author{
Maryam Karami NOGOURANI', Mohsen JANGHORBANI ${ }^{2}$, Parvin KHADEM ${ }^{3}$, Zahra JADIDI ${ }^{4}$, Shahriar JALALI ${ }^{4}$ \\ 1- DDS, MSc, Associate Professor, Department of Pediatric Dentistry, Dental School, Islamic Azad University Khorasgan Branch, Isfahan, Iran. \\ 2- PhD, Professor of Epidemiology, Department of Epidemiology, Isfahan University of Medical Sciences, Iran. \\ 3- DDS, MSc, Assistant Professor, Department of Community Dentistry, Dental School, Islamic Azad University Khorasgan Branch, Isfahan, Iran. \\ 4- DDS, MSc, Graduate student (Doctor degree), Dental School, Islamic Azad University Khorasgan Branch, Isfahan, Iran.
}

Corresponding address: Dr Maryam Karami - Department of Pediatric Dentistry, Dental School, Islamic Azad University Khorasgan Branch, Arghavanieh , Isfahan, Iran - Phone +98 9131146910 - FAX: +98 3117764274 - e-mail: maryam_karami@yahoo.com

Received: October 08, 2010 - Modification: June 09, 2011 - Accepted: July 08, 2011

\section{ABSTRACT}

$\mathrm{O}$ bjectives: The objective of this one-year clinical study was to investigate the effect of two adhesive systems (Adper Single Bond, a two-step etch-and-rinse and Clearfil SE Bond, a two-step self-etch system) on pit-and-fissure sealant retention in newly-erupted teeth. This study compared the success of the sealants in mesial and distopalatal grooves with and without these two adhesive systems. Material and Methods: In a clinical trial, 35 children aged 6-8 years undergoing sealant placement were recruited. This one-year clinical study scored 70 mesial and 70 distopalatal sealants of newly-erupted permanent maxillary first molar, with a split-mouth design. All children received sealant alone in one permanent maxillary molar tooth. Children were randomized into two groups. One group received Self-Etch (SE) bond plus sealant and the other group received Single Bond plus sealant in another permanent maxillary molar tooth. Clinical evaluation at 3, 6 and 12 months was performed and the retention was studied in terms of the success and failure. Results: The success rate of sealant in the distopalatal groove, using SEB at 3, 6 and 12 months was $93.3 \%$ (95\% CI: $68.0,99.8), 73.3 \%$ (95\% CI: $44.9,92.2)$ and $66.7 \%(95 \%$ $\mathrm{CI}: 38.4,88.2)$, respectively. It was greater than that of the distopalatal groove in SB group with a success rate of $62.5 \%(95 \% \mathrm{CI}: 35.4,84.8), 31.3 \%(95 \% \mathrm{CI}: 11.8,58.7)$ and $31.3 \%(95 \% \mathrm{CI}: 11.8,58.7)$, at the three evaluation periods. The success rate of sealant in the mesial groove using SEB was $86.6 \%$ (95\% CI: $59.5,98.3), 53.3 \%(95 \%$ CI: $26.6,78.7)$ and $53.3 \%(95 \%$ CI: $26.6,78.7)$, while this was $100 \%(95 \%$ CI: 79.4 , $100.0), 81.3 \%(95 \% \mathrm{CI}: 54.4,96.0)$ and $81.3 \%$ (95\% CI: $54.4,96.0)$ using SB, at 3,6 and 12-month evaluation periods. Conclusions: These results support the use of these two bonding agents in pit-and-fissure sealants under both isolated and contaminated conditions. Further, SE bond seemed to be less sensitive to moisture contamination.

Key words: Pit and fissures sealants. Dental adhesives. Bonding agent. Clinical trials.

\section{INTRODUCTION}

Dental caries are a public health problem. Young permanent molars have been shown to be at an increased risk for caries because of the complex nature of their occlusal surface morphology. Preventive strategies including fissure sealant have made a significant contribution to decreased caries on sealed occlusal surfaces ${ }^{24,30}$. Although sealant shave been shown to be successful preventive restorations, failure rates have been reported between $5 \%$ and $10 \%$ each year ${ }^{23}$. Fissure sealant fails to succeed mainly due to lack of adequate isolation and etched enamel contamination by saliva or gingival fluid ${ }^{12,13}$. Therefore, the stage of tooth eruption, the behavior of the child, the possibility of 
establishing adequate isolation by applying rubber dam or cotton roll are among the factors that should be taken into account in fissure sealant ${ }^{6,8}$.

The ideal time for pit-and-fissure sealants is immediately after tooth eruption in the oral cavity $^{8}$. However, the greatest risk of sealant failure, too, occurs soon after tooth eruption, when contamination with saliva and gingival fluid almost always is inevitable. In such a case, the distal marginal ridge and the palatal groove in maxillary molars and buccal groove in mandibular molars have just cleared the soft tissue ${ }^{5,18}$.

Adhesive agents have been used as mediating agents between the enamel surface and sealant. These materials have been advocated because of their low viscosity properties, which supposedly increase penetrability into occlusal pits and fissures ${ }^{15,21}$. Adhesives using self-etch techniques have shown inconclusive results regarding microleakage and bond strengths, when used as sealants or as mediating agents ${ }^{10,14,21}$. A number of studies have shown that the use of a bonding agent as an intermediary layer between contaminated enamel and sealant significantly reduces microleakage ${ }^{4,13,27}$, improves sealant retention and short-term clinical success $^{12}$.

The objective of this in vivo study, therefore, was to compare two adhesive systems [Adper Single Bond, a two-step, etch-and-rinse adhesive system and Clearfil Self-Etch (SE) Bond, a twostep, self-etch system] on sealant retention in newly-erupted teeth. The null hypothesis was that there is no significant difference between the two adhesive systems regarding sealant retention in newly-erupted teeth.

\section{MATERIAL AND METHODS}

Following institutional ethical committee approval and written informed child's parents or guardians consent, 35 children aged 6-8 years scheduled to undergoing pit-and-fissure sealant placement were approached to participate in this trial. Inclusion criteria were children with two sound newly-erupted permanent maxillary first molars and no evidence of substantial abnormalities in neurological, psychiatric, and any systemic diseases.

All children received sealant alone in one permanent maxillary molar tooth. Children were randomly assigned to two treatment groups of single bond plus sealant and SE bond plus sealant in other molar. The sealants were placed in 70 mesial and 70 distopalatal grooves of intact newly-erupted permanent maxillary first molars in accordance with a split-mouth design. Each subject received sealants on both maxillary first molars, one randomly assigned to receive sealant alone, while the other molar received a sealant under which was placed a bonding agent.

All sealants and adhesives were used with strict adherence to individual manufacturer instructions including: slow speed, cleaning of the surface with a plain pumice/water slurry, cotton roll isolation, 20-s phosphoric acid, gel etch (35\% Ultra Etch; Itradent Products, Inc., South Jordan, UT, USA), 15-s rinse, air dry, application of sealant (Clinpro; 3M ESPE), and 20-s light cure.

The placement of bonding agents prior to sealant application proceed as follows: for Single Bond (SB) (Adper Single Bond 3M ESPE): after acid etching, a layer of bonding agent was applied to the surface with a brush tip, blotted gently for 2-5 s, followed by 10 -s light curing.

For SE Bond (SEB) (Clearfil SE Bond Kuraray, Tokyo, Japan): after acid etching (upon manufacturer's recommendation for intact enamel), primer was applied to the entire surface, after waiting for 20-s and a mild air stream was used on the volatile ingredients to evaporate, the bond was applied with a brush tip, then made uniform with a gentle air stream followed by 10 -s of light curing. For all sealant applications, moisture was carefully controlled using accepted cotton-roll-isolation procedures. Clinical evaluation of each groove was performed at 3, 6 and 12-month follow-ups, using a No. 05 explorer and flat mirror.

Only two situations were considered for the outcome analysis: success (complete, intact sealant) and failure (marginal discoloration of any degree, partial or total loss of sealant). Ethically, in the event of failure, the fissures were resealed on elimination of the sample.

The study was powered $(80 \%)$ to detect (with a two-sided alpha of 0.05 ) a difference in retention rate of $10 \%$ between groups. The results for the groups that received sealant alone or bonding agent plus sealant were compared with chi-square or Fisher's exact test. All statistical tests were two-sided and $p<0.05$ was considered statistically significant. The analyses were done on a personal computer using SPSS for Windows (SPSS Inc., Chicago, IL, USA).

\section{RESULTS}

In this trial, 35 children participated: 17 in SE and 18 in SEB groups. Two children in SE group and 2 children in SEB group were excluded. The two treatment groups were generally matched at baseline with regard to age and gender. The total number of teeth surfaces scored was 140 , with 70 being mesial and 70 distopalatal sealants of newlyerupted permanent maxillary first molar.

In both SEB and SB groups, compared to the control groups (sealant-alone groups), the bonding 


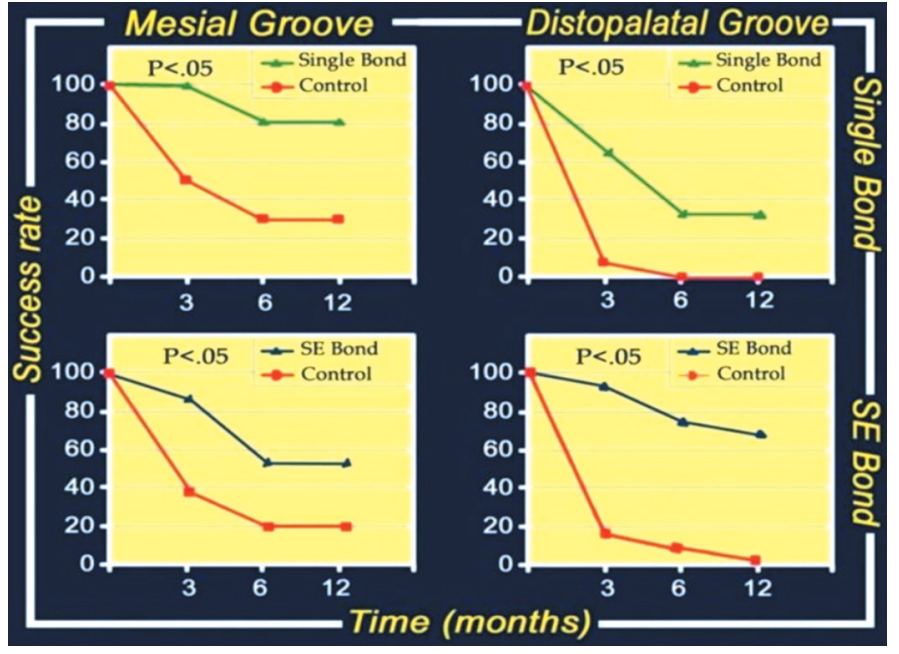

Figure 1- Success rate of the pit-and-fissure sealants in mesial and distopalatal grooves with and without previous use of the adhesive systems

Table 1- Comparison of SE and SEB groups in 31 patients with newly-erupted teeth 3-, 6- and 12-months after treatment with and without Single Bond and SE Bond adhesive systems

\begin{tabular}{ccccc}
\hline Variables & Single bond No. (\%) & Control group No. (\%) & Control group No. (\%) & Difference (95\% Cl) \\
\hline After 3 months & $60.0(31.8,88.2)^{* *}$ & $4(26.7)$ & $8(50.0)$ & $16(100.0)$ \\
After 6 months & $33.3(1.0,79.7)^{*}$ & $3(20.0)$ & $5(31.3)$ & $13(81.3)$ \\
After 12 months & $33.3(1.0,79.7)^{*}$ & $3(20.0)$ & $5(31.3)$ & $13(81.3)$ \\
\hline After 3 months & $80(58.7,100.0)^{* * *}$ & $2(13.3)$ & $1(6.3)$ & $10(62.5)$ \\
After 6 months & $60.0(31.8,88.2)^{* *}$ & $2(13.2)$ & $0(0.0)$ & $5(31.3)$ \\
After 12 months & $66.7(42.8,90.5)^{* *}$ & $0(0.0)$ & $0(0.0)$ & $5(31.3)$ \\
\hline
\end{tabular}

${ }^{*} \mathrm{P}<0.05,{ }^{* *} \mathrm{P}<0.01,{ }^{* * *} \mathrm{P}<0.001 . \mathrm{Cl}=$ Confidence interval

agents used in mesial and distopalatal grooves significantly improved the success of the sealant (Figure 1 and Table 1).

Another finding was in the control groups, the sealant success of the mesial groove was significantly greater than that of the distopalatal groove bordering gingival sulcus on the newlyerupted teeth $(p<0.05)$.

In SEB group, in addition to the above, the success of sealant therapy of the distopalatal groove was also greater than that of the mesial groove $(p<0.05)$. Unlike in the SEB, in the SB group, the outcome of the mesial groove was significantly better than that of the distopalatal $(p<0.001)$.

An analysis of the results of follow-up at 3, 6 and 12 months for SB and SEB groups indicated that the greatest failure rate occurred in all the sub-groups in the first 6 months.

Another finding was that the success rate for distopalatal groove in SEB at 3, 6 and 12 months with a success rate of $93.3 \%$ (95\% CI: $68.0,99.8)$, $73.3 \%(95 \% \mathrm{CI}: 44.9,92.2)$ and $66.7 \%(95 \% \mathrm{CI}$ : $38.4,88.2)$, respectively, was greater than that of the distopalatal groove in SB group with a success rate of $62.5 \%$ (95\% CI: $35.4,84.8), 31.3 \%(95 \%$ CI: $11.8,58.7)$ and $31.3 \%(95 \% \mathrm{CI}: 11.8,58.7)$, at the three evaluation periods, respectively.

On the contrary, the success rate of mesial groove sealant for the SEB group in both the 6and 12-month studies was significantly lower than that of the SB mesial groove sealant $(p<0.05)$. The success rate of sealant in the mesial groov, using SEB at 3, 6 and $12-$ month studies was $86.6 \%$ (95\% CI: 59.5, 98.3), 53.3\% (95\% CI: 26.6, 78.7) and $53.3 \%$ (95\% CI: 26.6, 78.7), respectively, while this was $100 \%$ (95\% CI: 79.4, 100.0), $81.3 \%(95 \%$ CI: $54.4,96.0)$ and $81.3 \%$ (95\% CI: 54.4, 96.0), respectively, using $\mathrm{SB}$.

\section{DISCUSSION}

This one-year clinical trial reports data on sealant retention in a difficult clinical situation (newly-erupted maxillary molars), focused on comparing the success rates of sealants in mesial and distopalatal grooves with and without two 
adhesive systems. In this trial, both SB and SEB use improved the success of the sealants under both isolated and contaminated conditions and thus the null hypothesis was not rejected. The group which received SEB seemed to be less sensitive to moisture contamination.

The children selected for this study were aged 6-8 with two newly-erupted maxillary permanent first molars. In this clinical condition, this is very difficult to isolate tooth and applying rubber dam is also impossible ${ }^{1,6}$. In the early eruption stages of the permanent maxillary first molar, the distopalatal groove is in close vicinity, or even contacting gingival sulcus at the distal and palatal area. However, the isolation of the mesio-occlusal groove can be performed in an easier manner. The results of this study also indicated that in control groups the failure rate of the distopalatal groove sealant was significantly greater than that of the mesial groove. Other studies also indicate that the failure rates on palatal surfaces are higher, often double the rates of failure observed in the occlusal sealants in the same patients ${ }^{9,18}$

The results of the present study indicate that in both SB and SEB groups, use of bonding agents in each mesial and distopalatal groove significantly increases the success rate of pit-and-fissure sealants therapy over sealant-alone groups. Although the studies focused on merits of using adhesive prior to pit-and-fissure sealants on contaminated and non-contaminated enamel are in conflict ${ }^{19,29}$, a large number of studies indicate increased bond strength, decreased microleakage and improved short-term clinical success. Using a hydrophilic bonding agent results in improved sealant retention rate and increased resin flow into deep fissures, especially those not completely dried ${ }^{7,11}$. The excellent wetting quality of HEMA has made it an essential part of many modern adhesive systems including these two bonding agents, promoting adhesion to either dry or moist enamel ${ }^{17}$.

Similar to this study, Feigal, et al. ${ }^{8}$ (2000) indicated that in a 36-month study, using SB in occlusal and palatal grooves significantly increased the success rate of pit-and-fissure sealants. Moreover, Torres, et al. ${ }^{26}$ (2005) stated that in both contaminated and non-contaminated groups, significantly higher shear bond strength was observed when a bonding agent was applied underneath the sealant.

Clearfil SE Bond is a mild $\mathrm{pH}(\mathrm{pH}=2)$ self-etch bonding agent. When applied to dentin or cut enamel, no extra acid etching step is necessary. However, some concern remains regarding the short-term and long-term bonding effectiveness of particularly mild $\mathrm{pH}$ self-etch adhesives on enamel ${ }^{3,25}$. Some manufacturers, Clearfil SE Bond's included, recommend the adjunctive use of phosphoric acid for bonding to uncut enamel which is prismless, hyper-mineralized and contains more inorganic material than the inner enamel layer. For this reason, in this study too, the enamel was acid-etched before using SEB ${ }^{22}$. Etching prior to using self-etch adhesive significantly increased the bonding effectiveness on enamel ${ }^{28}$, and decreased marginal defects ${ }^{20}$. Transmission electron microscopy (TEM) and field-emission gun scanning electron microscopy (Feg-SEM) revealed a clearly more-retentive surface when enamel was etched. However, in the non-etch group there was hardly any microscopically detectable resin tag formation in the enamel interface ${ }^{28}$. Not only the micromechanical retention, but also the chemical reaction between the functional monomers and residual hydroxyapatite are two mechanisms that self-etch adhesives use to create a significantly strong bond to the enamel ${ }^{28}$.

In SEB group, the sealant success rate in the distopalatal groove (with a higher risk of contamination) was greater than that of the mesial groove. However, unlike in SEB group, in the SB group, the sealant success was significantly better than that of the distopalatal group. On the other hand, the success rate of the distopalatal groove in SEB group was higher in all the three follow-up evaluation periods of 3, 6 and 12 months than that of the distopalatal groove in SB group. In contrast, the success rate of the mesial groove sealant for SEB group in the 6 and 12-month studies was significantly lower than that for the SB group.

All these findings in this study indicate the superiority of SEB in the distopalatal groove with a higher risk of saliva and moisture contamination and the superior performance of SB in the mesial groove with a lower risk of contamination. Apart from hydrophilic monomers that increase the wet ability of enamel especially when fissures are not completely dry, solvents such as ethanol in SB due to their volatility can displace water and improve bonding ${ }^{17}$. In uncontaminated conditions, etchand-rinse adhesives outperformed for marginal adaptation and retention to self-etch adhesives ${ }^{16}$. However, in over-wet conditions, ethanol in SB cannot completely remove the excessive moisture, so that water occupies the space that should optimally be filled with resin. Water and the other components of saliva, such as human and bacterial enzymes hydrolyze and plasticize the resin ${ }^{17}$. The result of the study conducted by Gomes-Silva, et al. ${ }^{11}$ (2008) also indicated the poorer performance of SB under contaminated conditions. The sensitivity of the technique of the etch-and-rinse systems and the probable inconsistency between the degree of demineralization and monomers infiltration have been leveled at the degradation of these adhesive systems in contact with a water environment ${ }^{31}$. 
The presence of acidic monomers in SEB systems, for instance the 10-MDP in the SEB, compared to previous systems renders the systems more hydrophilic and favors diffusion process ${ }^{23}$. Besnault and Attal $^{2}$ (2002) found that Clearfil SE Bond was less influenced by relative humidity than Scotchbond MultiPurpose. Self-etch adhesives are less sensitive to humidity, and thus the need of using a rubber dam is decreased ${ }^{2}$.

A review of the results of the follow-up at 3, 6 and 12 months indicated that the highest failure rate in all sub-groups occurred in the first 6 months, a finding that reinforces the need of follow-up examination within 6 months after placement of pit-and-fissure sealants.

\section{CONCLUSION}

Overall, using hydrophilic bonding agents increases the success rate of pit-and-fissure sealants. To improve the success of the pit-andfissure sealants in young, disabled or uncooperative children, basically on teeth which, for any reason whatsoever, are incapable of being sufficiently isolated, it is recommended to use pre-etching self-etch adhesive as an intermediary substance between the enamel and sealant.

\section{REFERENCES}

1- Bauer JR, Reis A, Loguercio AD, Barroso LP, Grande RH. Effects of aging methods on microleakage of an adhesive system used as a sealant on contaminated surfaces. J Appl Oral Sci. 2005;13:377-81.

2- Besnault C, Attal JP. Influence of a simulated oral environment on microleakage of two adhesive systems in Class II composite restorations. J Dent. 2002;30:1-6.

3- Borges MA, Matos IC, Dias KR. Influence of two self-etching primer systems on enamel adhesion. Braz Dent J. 2007;18:113-8. 4- Borsatto MC, Thomaz MY, Contente MM, Gomes-Silva JM, Mellara TS, Galo R, et al. Bonding agent underneath sealant: shear bond strength to oil-contaminated. Braz Dent J. 2010;21:50-4.

5- Dennison JB, Straffon LH, More FG. Evaluating tooth eruption on sealant efficacy. J Am Dent Assoc. 1990;121:610-4.

6- El-Kalla IH, Garcia-Godoy F. Effect of saliva contamination on micromorphological adaptation of single-bottle adhesives to etched enamel. J Clin Pediatr Dent. 1999;24:69-74.

7- Eminkahyagil N, Gokalp S, Korkmaz Y, Baseren M, Karabulut E. Sealant and composite bond strength to enamel with antibacterial/ self-etching adhesives. Int J Paediatr Dent. 2005;15:274-81.

8- Feigal RJ, Musherure P, Gillespie B, Levy-Polack M, Quelhas I, Hebling J. Improved sealant retention with bonding agents: a clinical study of two-bottle and single-bottle systems. J Dent Res. 2000;79:1850-6.

9- Futatsuki M, Kubota K, Yeh YC, Park K, Moss SJ. Early loss of pit and fissure sealant: a clinical and SEM study. J Clin Pediatr Dent. 1995;19:99-104.

10- Gillet D, Nancy J, Dupuis V, Dorignac G. Microleakage and penetration depth of three types of materials in fissure sealants: self-etching primer vs. etching: an in vitro study. J Clin Pediatr Dent. $2002 ; 26: 175-8$.
11- Gomes-Silva JM, Torres CP, Contente MM, Oliveira MA, PalmaDibb RG, Borsatto MC. Bond strength of a pit-and-fissure sealant associated to etch-and-rinse and self-etching adhesive systems to saliva-contaminated enamel: individual vs. simultaneous light curing. Braz Dent J. 2008;19:341-7.

12- Grande RH, Ballester R, Singer JM, Santos JF. Microleakage of a universal adhesive used as a fissure sealant. Am J Dent. 1998; 11:109-13.

13- Hebling G, Feigal RJ. Use of one-bottle adhesive as an intermediate bonding layer to reduce sealant microleakage on saliva-contaminated enamel. Am J Dent. 2000;13:184-91.

14- Hori M, Yoshida E, Hashimoto M, Kaga M, Sano H, Oguchi $H$. In vitro testing of all-in-one adhesives as fissure sealants. Am J Dent. 2004;17:177-81.

15- Irinoda $Y$, Matsumura $Y$, Kito $H$, Nakano T, Toyama T, Nakagaki $\mathrm{H}$, et al. Effect of sealant viscosity on the penetration of resin into etched enamel. Oper Dent. 2000;25:306-10.

16- Loguercio AD, Bittencourt DD, Baratieri LN, Reis A. A 36-month evaluation of self-etch and etch-and-rinse adhesives in noncarious cervical lesions. J Am Dent Assoc. 2007;138:507-14.

17- Meerbeek BV, Landuyt KV, Munck JD, Inoue S, Yoshida Y, Perdigão J, et al. Bonding to enamel and dentin. In: Summitt JB, Robbins JW, Hilton TJ, Schwartz RS, ed. Fundamentals of Operative Dentistry: a contemporary approach. $3^{\text {rd }}$ ed. London: Quintessence Publishing Co; 2006. p. 202-42.

18- Messer LB, Calache $\mathrm{H}$, Morgan MV. The retention of pit and fissure sealants placed in primary school children by Dental Health Services, Victoria. Aust Dent J. 1997;42:233-9.

19- Perdigão J, Carmo AR, Anauate-Netto C, Amore R, Lewgoy HR, Cordeiro $\mathrm{HJ}$, et al. Clinical performance of a self-etching adhesive at 18 months. Am J Dent. 2005;18:135-40.

20- Peumans M, Munck J, Van Landuyt K, Lambrechts P, Van Meerbeek $B$. Three-year clinical effectiveness of a two-step selfetch adhesive in cervical lesions. Eur J Oral Sci. 2005;113:512-8. 21- Pinar A, Sepet E, Aren G, Bölükbaşi N, Ulukapi H, Turan N. Clinical performance of sealants with and without a bonding agent. Quintessence Int. 2005; 36:355-60.

22- Shimada Y, Tagami J. Effects of regional enamel and prism orientation on resin bonding. Oper Dent. 2003;28:20-7.

23- Simonsen RJ. Pit and fissure sealant: review of the literature. Pediatr Dent. 2002;24:393-414.

24- Sundfeld RH, Croll TP, Mauro SJ, Briso AL, Alexandre RS, Sundefeld ML. Longitudinal photographic observation of the occurrence of bubbles in pit and fissure sealants. J Appl Oral Sci. 2006; 14:27-32.

25- Tay FR, Pashley DH, King NM, Carvalho RM, Tsai J, Lai SC, et al. Aggressiveness of self-etch adhesives on unground enamel. Oper Dent. 2004;29:309-16.

26- Torres CP, Balbo P, Gomes-Silva JM, Ramos RP, Palma-Dibb RG, Borsatto MC. Effect of individual or simultaneous curing on sealant bond strength. J Dent Child. 2005;72:31-5.

27- Tulunoğlu O, Bodur $H$, Uçtaşli M, Alaçam A. The effect of bonding agents on the microleakage and bond strength of sealant in primary teeth. J Oral Rehabil. 1999;26:436-41.

28- Van Landuyt KL, Kanumilli P, De Munck J, Peumans M, Lambrechts $P$, Van Meerbeek B. Bond strength of a mild self-etch adhesive with and without prior acid-etching. J Dent. 2006;34:7785.

29- Venker DJ, Kuthy RA, Qian F, Kanellis MJ. Twelve-month sealant retention in a school-based program using self-etching primer/ adhesive. Public Health Dent. 2004;64:191-7.

30- Vieira AL, Zanella NL, Bresciani E, Barata TJ, Silva SM, Machado $M A$, et al. Evaluation of glass ionomer sealants placed according to the ART approach in a community with high caries experience: 1-year follow-up. J Appl Oral Sci. 2006;14:270-5.

31- Yazici AR, Kiremitçi A, Celik C, Ozgünaltay G, Dayangaç B. A two-year clinical evaluation of pit and fissure sealants placed with and without air abrasion pretreatment in teenagers. J Am Dent Assoc. 2006;137:1401-5. 